\title{
GESTÃO DE PALETES NO NÉGOCIO DA CSN CIMENTOS*
}

\author{
Paulo Henrique da Silva Gomes ${ }^{1}$ \\ Marcus Paulo Moura Moutinho ${ }^{2}$ \\ Ubaldo Marques Silva Filho ${ }^{3}$ \\ Luigi Guarino Neto ${ }^{4}$ \\ João Mário Lourenço Filho ${ }^{5}$
}

\section{Resumo}

A melhoria contínua dos processos é fator fundamental para o sucesso do negócio. Avaliar as melhores práticas e propor soluções que equilibrem os custos e o uso consciente dos recursos naturais transformará o negócio sustentável e sólido. Com esse ideal foi realizado um estudo de viabilidade econômico-financeira e operacional para a implantação de uma nova metodologia na gestão de paletes do negócio cimentos. O estudo objetivou a implantação de um sistema integrado de paletes que permitiu uma gestão eficiente do negócio, sendo possível controlar os índices de paletes disponíveis para a produção, paletes em reparo, paletes sucateados e balanceamento de estoque entre fábricas e centros de distribuição, contribuindo para uma redução da necessidade de compra de novos paletes. Além disto, propôs também a implantação de uma oficina de paletes dentro das fábricas garantindo um melhor processo de triagem de paletes que contribuiu para a redução do tempo de parada das linhas produtivas por problemas de paletes fora de padrão operacional.

Palavras-chave: Sustentabilidade; Paletes; Gestão de Estoque; Gestão de compras.

\section{PALLET MANAGEMENT AT CSN CEMENT BUSINESS}

\begin{abstract}
Continuous process improvement is a key factor for business success. Evaluate best practices and propose solutions that balance the costs and the conscious use of natural resources become sustainable and solid business. With this ideal was a study of economic-financial and operational feasibility for the implementation of a new methodology in business pallet management cements. The study aimed at the implementation of an integrated pallet allowing efficient management of the business, and can control the pallet indexes available for production, repair pallets, scrapped pallets and inventory balancing between plants and distribution centers, contributes to reducing of purchasing new pallets. In addition, also proposed the implementation of a pallet workshop ensuring better pallet screening process that contributed to reducing the downtime of production lines by problems pallet off standard operating.
\end{abstract}

Keywords: Sustainability; Pallets; Inventory management; Purchasing management.

1 Administrador, Companhia Siderúrgica Nacional. Via Sergio Braga, no 272 - CEP 27260-390 Ponte Alta, Volta Redonda, RJ, Brasil.paulo.gomes@csn.com.br

2 Engenheiro, Companhia Siderúrgica Nacional. Via Sergio Braga, no 272 - CEP 27260-390 - Ponte Alta, Volta Redonda, RJ, Brasil. marcus.moutinho@csncimentos.com.br

3 Administrador, Companhia Siderúrgica Nacional. Av. Faria Lima no 3400 - CEP $04538-132$ - Itaim Bibi, SP, Brasil. ubaldo@csn.com.br.

4 Engenheiro, Companhia Siderúrgica Nacional. Av. Faria Lima no 3400 - CEP $04538-132$ - Itaim Bibi, SP, Brasil. luigi.neto@csn.com.br

5 Engenheiro, Companhia Siderúrgica Nacional. Av. Faria Lima no 3400 - CEP 04538-132 - Itaim Bibi, SP, Brasil. joao.lourenco@csn.com.br 


\section{INTRODUÇÃO}

A CSN possui duas fábricas de cimento, sendo uma localizada em Volta Redonda, dentro complexo industrial Presidente Vargas e a segunda unidade localizada na cidade de Arcos em Minas Gerais, juntas essas plantas possuem capacidade produtiva de 4,8 milhões de toneladas/ano, tendo como principais matérias-primas no seu processo de produção: (1) escória de alto forno, proveniente do processo siderúrgico da usina de aços planos, (2) calcário / clínquer, extraído e beneficiado na mina da CSN em Arcos-MG, (3) Pozolana e (4) Gesso, adquiridos através de fornecedores externos homologados. Buscando sinergia nos negócios e redução dos custos logísticos o negócio cimentos da CSN foi desenhado para receber suas matérias primas e insumos através dos modais rodoviário e ferroviário, atualmente o maior volume movimentado para o abastecimento de matérias-primas das plantas é movimentado através de ferrovia, conforme figura 1.

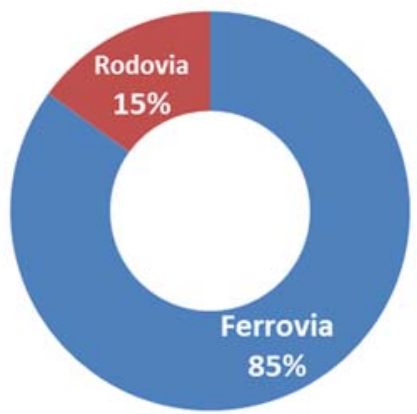

Gráfico 1. Share Ferro x Rodo abastecimento de matérias primas

Após o recebimento das matérias-primas, iniciasse o processo de fabricação do cimento, onde é realizada a mistura das matérias-primas de acordo com tipo de cimento que será produzido, em seguida essa mistura segue para as moagem onde se obtém o cimento puro, a partir desse processo pode-se adicionar outros componentes ao produto para se adquirir propriedades e características, a partir disso, o cimento produzido é armazenado em silos estando disponível para o processo de ensacamento ou venda direta a granel. Abaixo quadro do percentual de produção ensacado x granel no ano de 2015.

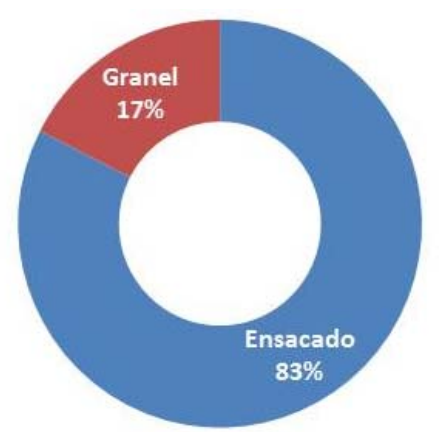

Gráfico 2. Produção Granel x Ensacado 2015

Para atendimento da produção de cimento ensacado, houve em 2015 uma demanda de 1,03 milhões de paletes.

Com o objetivo de realizar uma gestão eficiente no processo de paletes, foi desenvolvido um projeto que visa criar sinergias entre os estoques de paletes nas 
unidades produtivas e centros de distribuição e reutilização dos paletes através de um processo eficiente de triagem e seleção.

\section{MATERIAIS E MÉTODOS}

Este trabalho é resultado de reuniões realizadas ao longo do ano de 2015. Foram discutidas ações, ideias e planejamentos oriundos destes encontros, com participação de profissionais do setor produtivo e logístico.

A metodologia adotada nestes encontros foi o Método de Melhorias PDCA [2], que é uma ferramenta da qualidade fundamentada em conceitos da administração clássica, conforme Taylor [3] e Fayol [4], os quais devem ser implementados de forma sequencial, por meio de módulos, iniciando-se pela estruturação do processo, tornando-o mensurável e repetitivo. Cada etapa está estruturada nas seguintes fases abaixo com seu grupo de atividades e o seu desenvolvimento será detalhado a seguir.

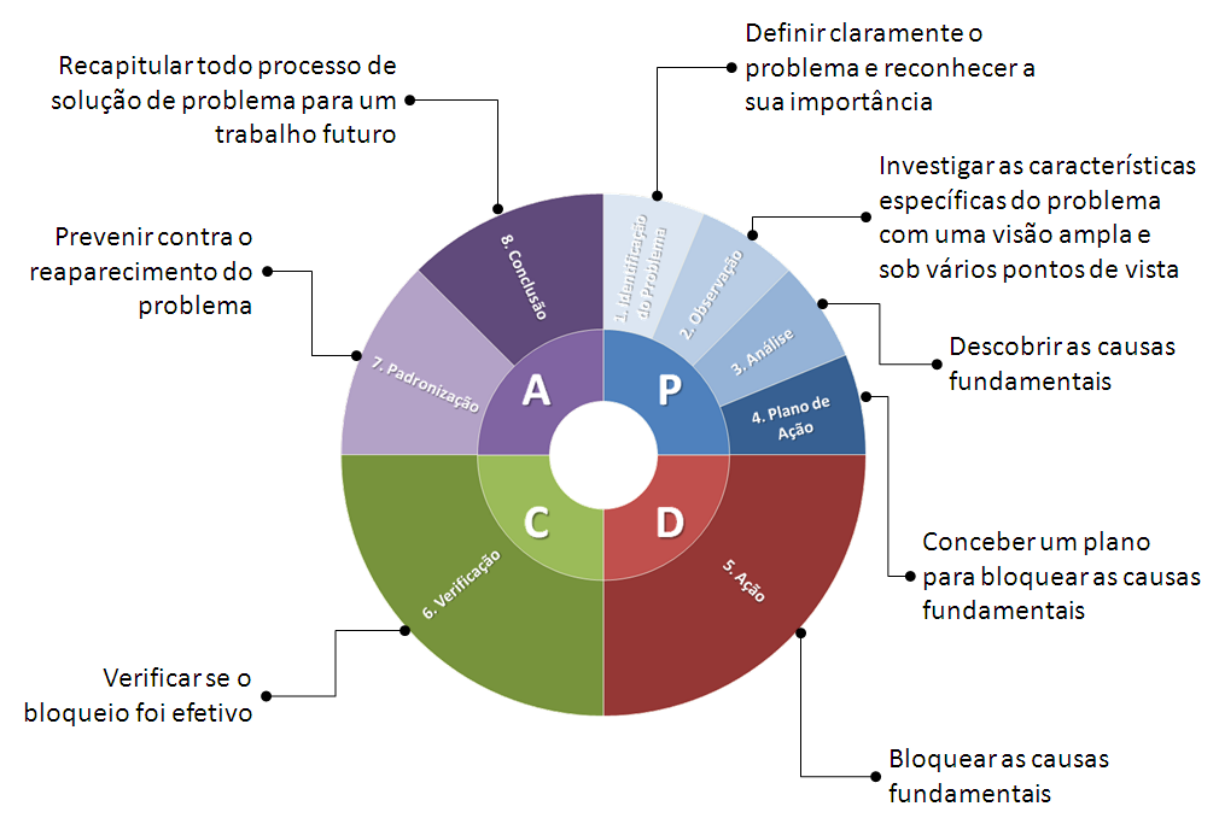

Figura 1. Ciclo PDCA.

\subsection{Processo de Paletização}

Cada planta da CSN Cimentos possui dois sistemas de ensacamento/paletização. $O$ processo de ensacamento é realizado de forma automatizada, garantido o peso estabelecido de $50 \mathrm{~kg}$./saco. O processo de paletização pode ser ajustado para realizar o empilhamento conforme demanda do cliente, atualmente o sistema está parametrizado para a paletização de 35 sacos/palete, gerando um peso total líquido de $1.750 \mathrm{~kg} /$ por palete.

Com essa configuração de ensacamento e paletização, a capacidade produtiva das plantas de Volta Redonda e Arcos é de aproximadamente 10,4 milhões de sacos por mês, gerando uma demanda de 296 mil paletes.

Após o processo de ensacamento/paletização, os paletes com cimento são armazenados no estoque e estão disponíveis para venda, podendo este ser realizado diretamente da planta ou através dos centros de distribuição. 


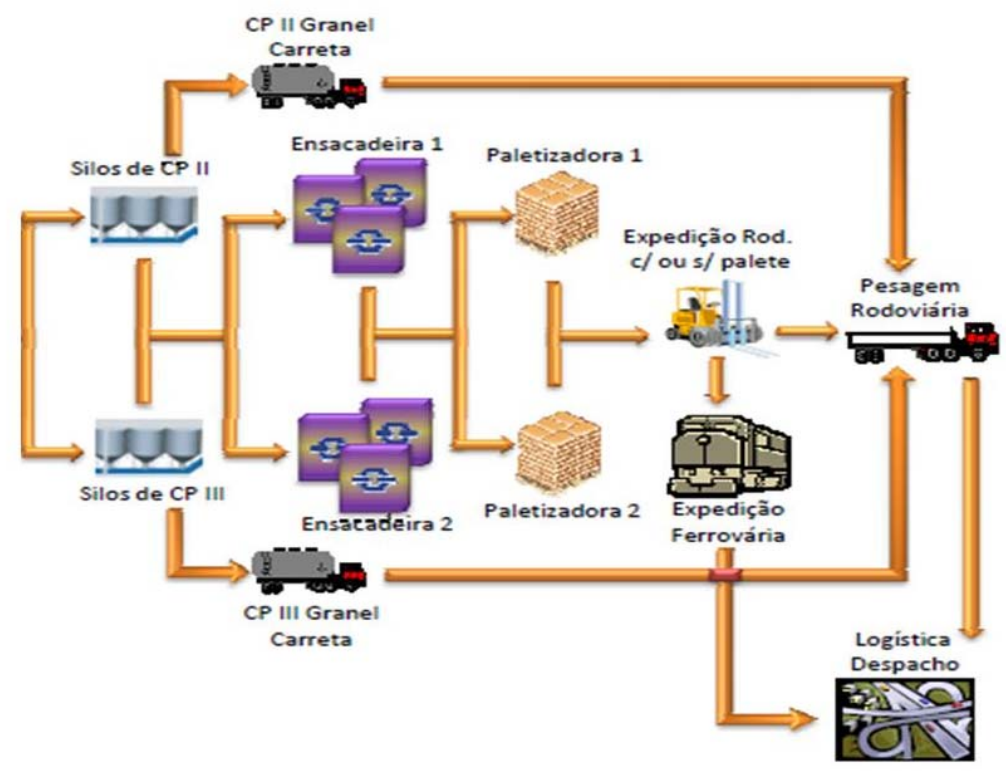

Figura 2. Sistema de ensacamento e paletização do sistema Volta Redonda

\subsection{Processo de Triagem e Seleção de Paletes}

As paletizadoras podem ser abastecidas com paletes novos ou reutilizados, dessa forma os veículos que realizam a retirada de cimento nas plantas ou centros de distribuição só podem carregar se estiverem com paletes vazios, realizando assim a troca de paletes vazios por paletes cheios.

Os paletes novos ou reformados que chegam diretamente dos fornecedores homologados da CSN são armazenados em área definida e ficam disponíveis para a produção.

Os paletes que vieram nos caminhões através do processo de troca são descarregados na área de triagem, onde é feita uma inspeção. Os requisitos para a definição de conformidade do palete são estabelecidos pela área produtiva juntamente com o fabricante do sistema de paletização.

Durante a inspeção, os paletes são classificados entre: (1) paletes bons, (2) paletes para reforma e (3) paletes para sucata.

Após a seleção, os paletes conformes são disponibilizados para a produção, os paletes definidos como reparo são encaminhados para empresas externas que realizam os reparos e os paletes sucateados são encaminhados para o entreposto de resíduos para posterior venda como sucata de madeira.

\subsubsection{Especificação dos Paletes}

O paletes utilizados na operação do cimento possuem as seguintes medidas $1,0 \mathrm{~m} x$ $1,2 \mathrm{~m}$, e peso aproximado de $35 \mathrm{~kg}$. 


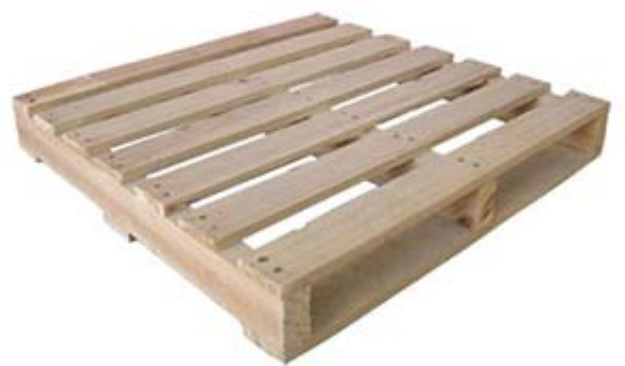

Figura 3. Palete padrão para condicionamento de cimento ensacado.

\subsubsection{Consumo de Madeira}

O consumo médio de madeira para a confecção de um palete novo é em média de $0,059 \mathrm{~m}^{3}$, no ano de 2013 foram adquiridos 183.273 paletes, no ano de 2014 o volume de paletes comprados foi de 190.182, conforme quadro abaixo.

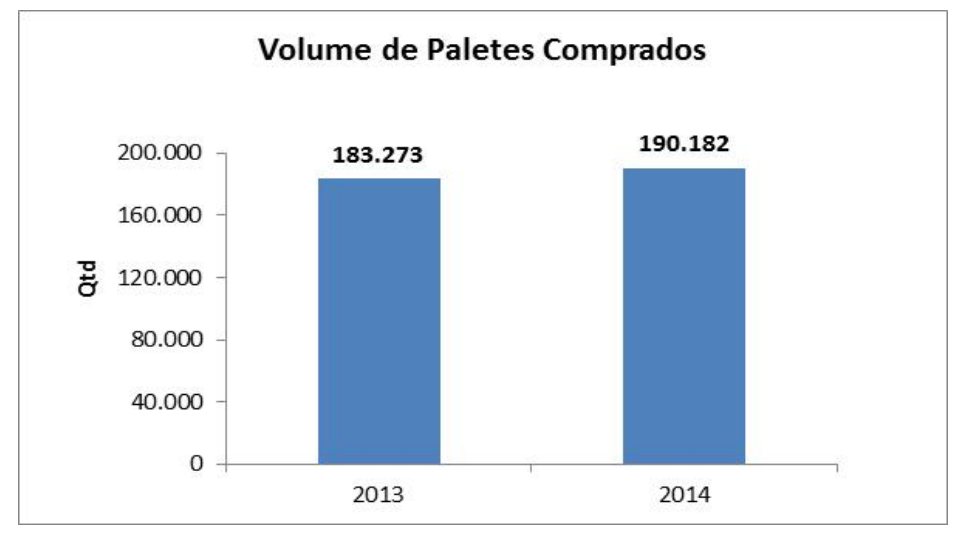

Gráfico 3. Volume anual de paletes comprados

No processo de reforma o consumo médio de madeira é de $0,012 \mathrm{~m}^{3}$, no ano de 2013 foram reformados 335.912 paletes, no ano de 2014 o volume de paletes reformados foi de 347.371 paletes, conforme quadro abaixo.

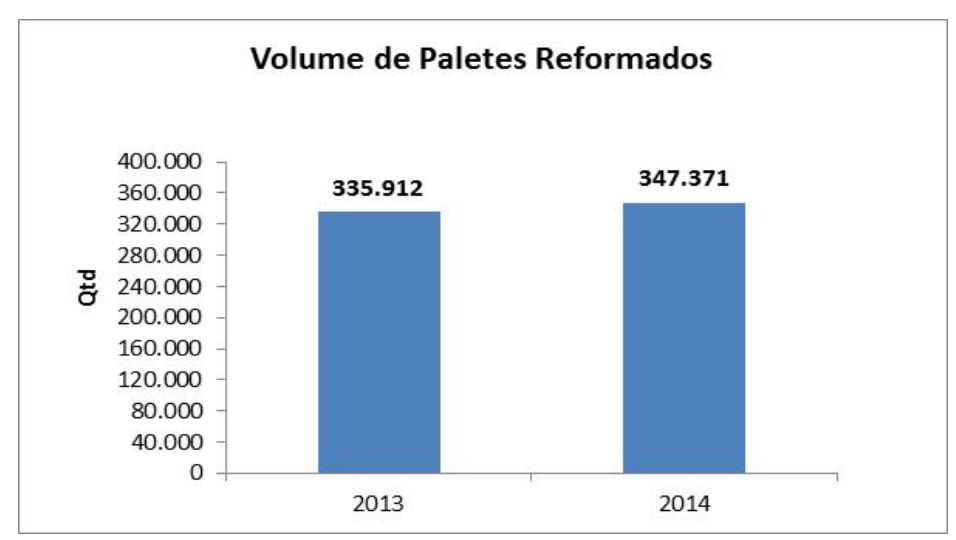

Gráfico 4. Volume anual de paletes reformados

Dessa forma, foram consumidos entre produção de paletes novos e reformados no período de 2013 e 2014 um total de $30.233 \mathrm{~m}^{3}$ de madeira, volume equivalente a 125 mil árvores, considerando uma árvore da espécie Eucalyptus urophylla, conhecida como Eucalipto, com o volume médio de rendimento da tora sem casca de $0,2416 \mathrm{~m}^{3}$. 


\section{RESULTADOS E DISCUSSÃO}

Realizando uma análise do processo após a implantação do sistema de gestão de paletes e com melhorias operacionais implantadas, observam-se ganhos significativos em vários aspectos.

\subsection{Novo Processo de Triagem e Seleção de Paletes}

Para o aumento da eficiência do processo de triagem e seleção de paletes, foi criado um novo local para a realização dessa atividade onde toda a equipe operacional da CSN e da empresa contratada recebeu novo treinamento dos procedimentos de seleção, manuseio e segregação dos paletes, também houve um workshop com a empresa de triagem de paletes e do fornecedor do sistema de paletização, foram discutidas novas oportunidades para o reaproveitamento dos paletes, aumentando assim sua vida útil, reduzindo a demanda de compra e das paradas da paletizadora por problemas relacionados à paletes.

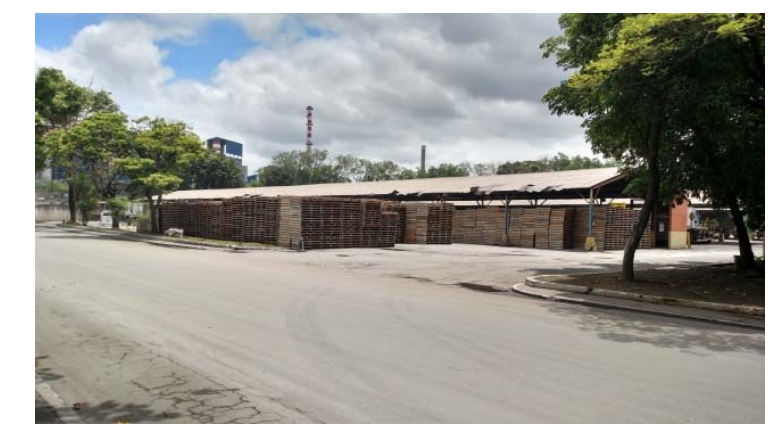

Figura 4. Área de triagem e seleção de paletes, unidade Volta Redonda

\subsection{Implantação do Sistema de Gestão de Paletes}

Desenvolvido pela equipe de projetos logísticos da CSN, o sistema de gestão de paletes tem por objetivo realizar o controle de toda a cadeia de paletes do negócio cimentos.

Para o desenvolvimento dessa ferramenta, foi realizado o mapeamento de todo o fluxo operacional do palete, além de reuniões e discussões com as áreas responsáveis do negócio.

O Sistema de gestão de paletes, recebeu o nome de Pallet Cell, através desse sistema a equipe operacional consegue controlar os estoques de paletes dentro das plantas e centros de distribuição, além de realizar o controle de paletes em reforma e quantidade sucateada. O sistema permite avaliar os níveis de estoque, auxiliando na tomada de decisão para a compra de novos paletes ou o balanceamento de estoque entre unidades, o que contribuiu significativamente para a redução de custo na aquisição de novos paletes.

Através dos relatórios extraídos do sistema de paletes é possivel controlar os índices de perda e quantidade de paletes enviados para reforma em fornecedores externos, atuando assim com os prestadores de serviço para o aumento da qualidade da triagem realizada internamente e qualidade do serviço prestado pelos fornecedores externos. Abaixo imagem da tela principal do sistema de paletes. 


\section{$35^{\circ}$ Logística}

\section{ISSN 1982-985X}

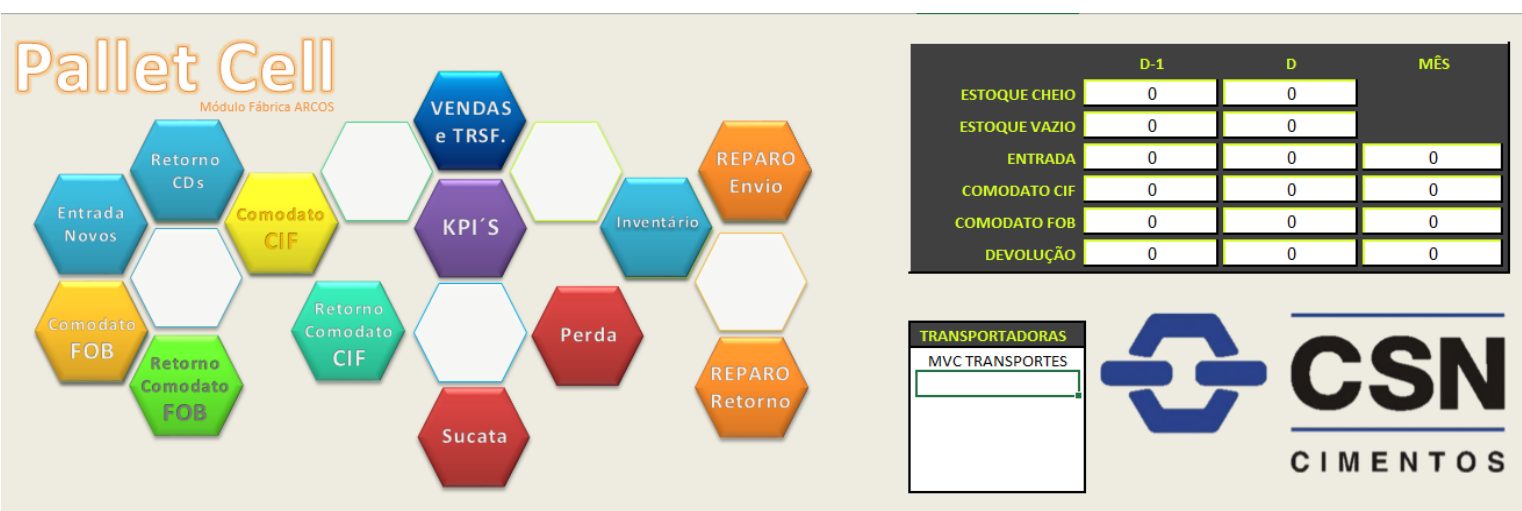

Figura 5. Painel principal do sistema de paletes

Além do sistema, a equipe de projetos desenvolveu um modelo de governança, com reuniões mensais para o acompanhamento dos indicadores de paletes, através desse comitê foram definidas metas mensais e anuais para aquisição de novos paletes, sucateamento de paletes e variações de inventário.

\subsection{Custo Operacional}

Com o aumento da eficiência de triagem de paletes e reforma externa, houve uma redução no volume de compra de paletes. Entre 2014 e 2015 houve uma redução de 1,18 milhões (23\%), para 2016 espera-se uma redução de 2,03 milhões (39\%), comparados a 2014.

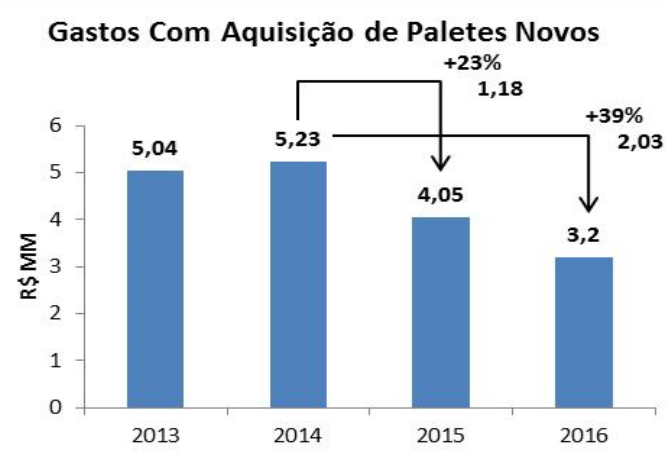

Gráfico 5. Gasto com aquisição de paletes novos em R\$MM

\subsubsection{Aumento da Produtividade de Paletes}

Com as ações realizadas o tempo médio mensal das paradas de produção por problemas de palete caíram $48 \%$, conforme gráfico abaixo.

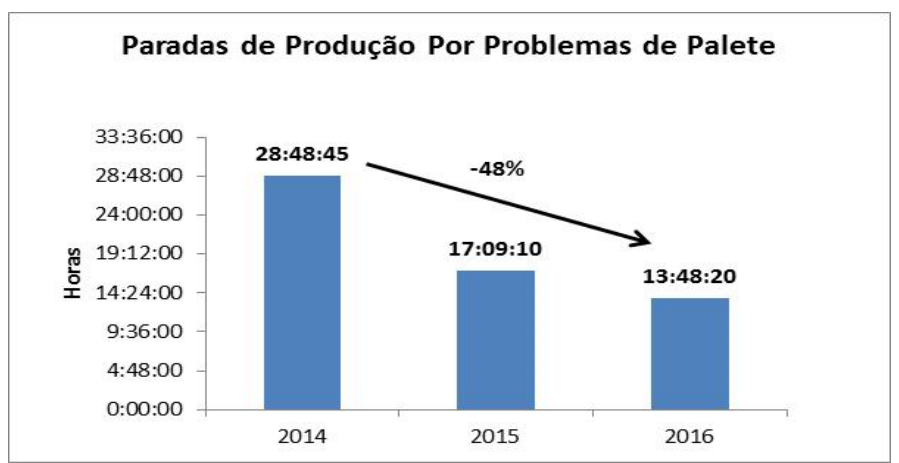

Gráfico 6. Média mensal das paradas de produção por problemas de palete 


\subsubsection{Aumento da Capacidade de Triagem de Paletes}

Com as ações realizadas a capacidade de triagem de paletes aumentou $23 \%$, conforme gráfico abaixo.

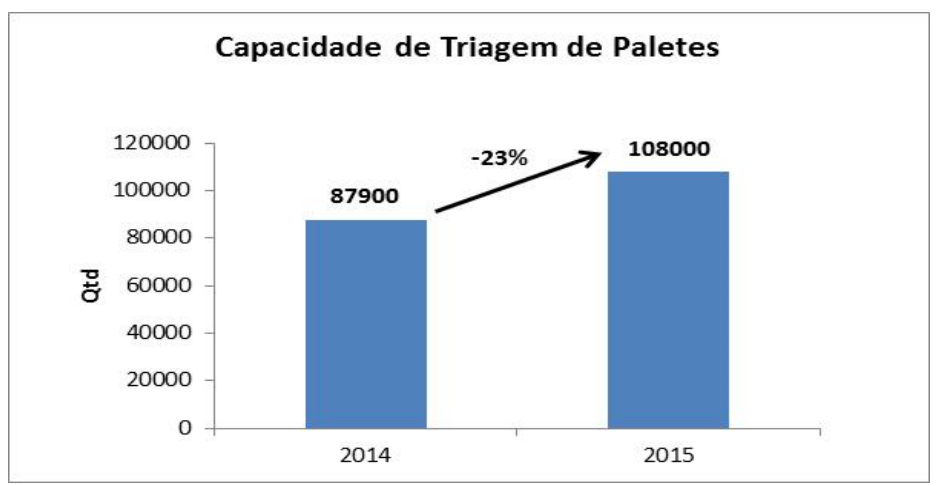

Gráfico 7. Capacidade mensal de triagem de paletes

\subsubsection{Redução do Consumo de Madeira}

Com a redução da aquisição de novos paletes e aumento da reutilização dos paletes usados, houve uma redução de 23\% em 2015. Para 2016 a redução é muito significativa de $81 \%$ no consumo de madeira, conforme quadro abaixo, contribuindo para a sustentabilidade no processo logístico.

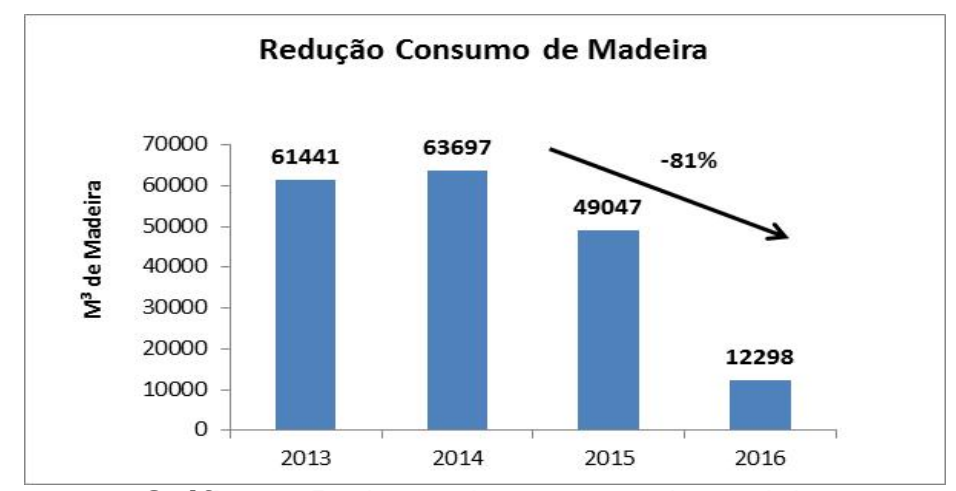

Gráfico 8. Redução do consumo de madeira

\section{CONCLUSÃo}

A implantação do sistema de gestão e a melhoria do processo de triagem e seleção de paletes geram resultados economicamente viáveis e ajudam na preservação de recursos naturais, dando sustentabilidade ao negócio. Além disso, dão condições mais seguras para os funcionários envolvidos no processo.

Através da gestão eficiente do processo foi possivel reduzir o consumo de paletes novos aumentando a reutilização dos paletes usados, com isso a CSN reduziu o consumo de madeira em $81 \%$ em sua operação, isso significa que anualmente 51,3 mil árvores deixarão de ser cortadas e esse volume representa 114 campos de futebol. A CSN tem por objetivo continuar a desenvolver ações visando à sustentabilidade, pois entende que estas soluções são mais do que uma busca de alternativas à redução de custos operacionais, projetos como estes contribuem substancialmente para o uso racional dos recursos naturais. 


\section{REFERÊNCIAS}

1 IBGE: Instituto Brasileiro de Geografia e Estatística [página da internet]. Brasil, 2013 [acesso em 04 fev. 2014]. Disponível em:

http://www.ibge.gov.br/home/estatistica/economia/pibmunicipios/2011/default_pdf.shtm.

2 ANDRADE, F. F. O Método de Melhorias PDCA. 2003. Dissertação (Mestrado em Engenharia de Construção Civil e Urbana) - Escola Politécnica, Universidade de São Paulo, 2003.

3 TAYLOR, Frederick Wislow. Princípios de administração científica. 8 ed. São Paulo: Atlas, 1990.

4 FAYOL, Henry Administração industrial e geral: previsão, organização, comando, coordenação, controle. 10. a ed. São Paulo: Atlas, 1989.

5 Scanavaca Junior L, Garcia JN. Rendimento em madeira serrada de Eucalyptus urophylla. In: Scientia Forestalis. Instituto de Pesquisas e Estudos Florestais. n.50 (1996). Piracicaba: IPEF, 1996. p. 32-43. 